\title{
Conventional - and Cone Beam - CT - Derived Stereolithographic Surgical Guides in the Planning and Placement of Dental Implants
}

\author{
Volkan Arısan \\ Department of Oral Implantology, Faculty of Dentistry \\ Istanbul University \\ Turkey
}

\section{Introduction}

The prevalence of tooth loss and edentulism is still posing a serious health problem especially for the elderly population. A removable denture was the only option in the treatment of total edentulism. However, serious complaints related to poor retention, mastication and perception of the prosthesis are common among edentulous patients (Raghoebar et al., 2000).

The discovery of osseointegration, -the direct bone contact to the load bearing titanium implant surface under 100X light microscopy- has led to a radical change in the rehabilitation of the edentulous patients. Especially upon the loss of posterior teeth, removable prosthesis was the only available option for patients suffering from severe decay, periodontal or root fracture problems (Lekholm, 1985). Anchorage of such removable prosthesis to the existing dentition yielded additional stress on the remaining teeth and increased the risk of decay in case of insufficient patient hygiene. Osseointegrated dental implants were especially vital for totally edentulous mandible which in other case will likely to result with an unsatisfactory denture due to various muscle attachments and tongue activity. With the help of orthopantomogram (known as panoramic x-rays) the vertical available bone height in mandibular symphisis was evaluated and the longest possible implant fixture (the only available implant diameter was the $3.75 \mathrm{~mm}$ ) was inserted after a surgical flap exposure. The implants were left to undisturbed healing for an approximate of 4 to 6 months. Following the osseointegration period a second surgery was performed for uncovering the implants and restorative phase (George et al., 1985).

Since then many technological advances have been accomplished from the titanium surface enhancements to the prosthetic aspect of the implant dentistry allowing better satisfaction of the patients' needs. Unlike early implant-supported hybrid prosthesis, the acceptable standard of care in implant dentistry requires not only the restoration of the lost function but also the appearance of the natural anatomy. This has become a criterion of success in the maxilla where the facial expression is conveyed through a pleasant aesthetic smile. Accurate positioning of the implant fixture has therefore become extremely critical to ensure a "natural" look (Belser et al., 1996).

Various attempts were undertaken to improve the relation of the implant positions and the prosthetic plan (Akca et al., 2002). In order to incorporate prosthetic information in the 
planning stage, the so known basic conventional implant placement approach was revised and called as "backwards planning" (Gotfredsen and Karlsson, 2001). With the use of radiopaque markers (Basten and Kois, 1996), the ideal position of the final prosthesis could be visualized on the x-rays which and they were transferred to the patients' mouth by a custom surgical template (Basten, 1995). The use of these templates provided help to some degree in partially edentulous cases. Furthermore, the inclusion of three dimensional (3D) tomographic data also assisted in deciding the implant diameter and axial inclination (Blanchet et al., 2004). From a prosthetic point of view, the parallelism of the implants would provide significant ease of clinical handling during the restoration phase. However due to trajectory of the jaws the parallel placement of multiple implants is extremely difficult. Also there is a risk of lethal haemorrhages or neural injuries as a result of the collision of the drills and/or implant apex were reported (Kalpidis and Setayesh, 2004).

\section{Recent radiographic examination methods in oral implantology}

Similar to many of those minor surgical interventions in dentistry ,the planning is generally based on the two-dimensional images of the radiographic techniques such as, peri-apical, orthopantomogram (panoramic x-ray), sephalometric and occlusal. Among these four techniques the two mentioned former are the most commonly used (Amet and Ganz, 1997). All these methods, however, are subject to distortion, blurring and also do not provide any information regarding the z-dimension; the "bone thickness". Consequently, clinical implant dentistry quickly recognised the importance of tomographic imaging (Klein et al., 1993) and its interactive implementation in the computer environment via a dedicated "implant planning" software (Rosenfeld et al., 2006). The technologic advances led emerging of newer and more specific imaging instruments such as cone-beam computed tomography (CBCT). The lack of sufficient comparative studies coupled with the rapidly evolving technologies (Reddy et al., 1994), however, has revealed many doubtful aspects of the recently marketed tomographic scanners which are briefly discussed below.

\subsection{Multi-slice computed tomography (CT)}

Conventional multi-slice CT was primarily developed for medical imaging of the body such as abdominal pathologies and investigation of the extremities. The sophisticated tubedetector assembly rotates $360^{\circ}$ along the axis of the scan area which is positioned by the table the patient is lying on. Each increment of the patient induces the rotation of the tubedetector assembly and consequent radiation exposure. The resulting transversal images are then transferred to a computer with dedicated software. Thanks to the advanced tubedetector assembly, the released ionizing energy of the ray of x-ray photons can be calculated to construct various diagnostic parameters with robust accuracy. Amongst these parameters, the Hounsfield unit is the most widely utilized parameter which is used for the assessment of the bone density on the basis of the gray-density values. By the attenuation of the $x$-ray energy to the air $(-1000 \mathrm{HU})$ and water $(0 \mathrm{HU})$ local bone density can be objectively measured on a quantitative basis (Shapurian et al., 2006). The measured gray density values may help predicting the local density of the implant recipient bone (Turkyilmaz et al., 2007). Due to complex structure and space needs, multi-slice CT scanners are operable in hospitals and/or radiology canters. 


\subsection{Cone-beam computed tomography (CBCT)}

Advancements in the computer processing and the reconstruction process as well as the mathematical conversion algorithms used for the CT led emerging of a new approach that is based on rendering "volumes" instead of "slices" (Araki et al., 2004). As opposed to the $\mathrm{CT}$ where a full $-360^{\circ}$ turn of the tube-detector assembly is required for each slice, in the CBCT the whole image of the object to be screened is "radiated" with an array of conicrays (Arai et al., 1999). The resulting data is then transferred to the computer and the axial, sagittal or frontal views are re-formatted by the computer according to the user demand. As a result of single-turn of the x-ray source the emitted dose (and relevant scanning time) is significantly lower than the CT (Carrafiello et al., 2010). This was a result of the re-designed tube assembly which emits remarkably lower doses of radiation as compared to the multi-slice CT.

As opposed to the multi-slice CT, the cone-beam CT scanners are quite small and have become available in size of an orthopantomogram (panoramic) device. This technology was primarily developed for cardiovascular purposes and promising outcomes led extension to different disciplines such as dentistry. The first generation of CBCT machines was equipped by an "image-intensifier" detector; a CMOS or CCD based technology used mainly in the digital camera industry. The resulting images were rather sufficient for visual examination purposes. However, in certain circumstances the images were subjected to severe distortion in terms of dimensional accuracy. Moreover, areas with high density caused heavy halation and beam hardening effects (Katsumata et al., 2006). Later use of flat-panel amorphoussilicone detectors improved the accuracy of the images but also led a slight increase in the emitted radiation dose (Baba et al., 2002). The efficacy of the CBCT-based grey-density values as compared to the CT-based Hounsfield unit (HU) is, however, unclear.

\section{Stereolithography and biomodelling in implant dentistry}

The need of a rapid 3D model of the computer-aided-designed (CAD) components in particular industries (i.e. automotive, space craft jewellery) leaded emerging complex technologic advances. The term "streolithography" (abbreviated as SLA or SL) first introduced in 1986 by Charles W. Hull, defines the method and apparatus for making solid objects by successive printing of light-curable material one on top of the other (Asberg et al., 1997). The procedure is entirely computer-controlled and named by various tags such as "3D printing", "additive manufacturing", "rapid manufacturing/prototyping" etc. This process was termed as "biomodelling" in the medicine and initially used to obtain 3D models of the particular bones. Thanks to the realistic dimensions of the models the clinicians were able to explore the future surgical site and decide particular plans specific to the local bone geometry of the patient. Biomodelling is widely used especially in cranial and spinal surgery.

\subsection{Virtual dental implant planning on reformatted CT images}

The need of a thorough planning of the dental implants prior to the surgical placement yielded emerging of many implant planning software on the market. The ability of working on true-sized 3D models is however, featured in only few of them. With the help of the advanced capabilities of some software, the clinician may outline critical anatomy (i.e. n.alveolaris, sinus maxillaris), prosthetic priorities and special circumstances which can never be assessed without exploring the actual surgical site. This may not only prevent the occurrence of adverse outcomes but can also diminish the stress on the surgeon in the surgical theatre (Rosenfeld et al., 2006); (Fig. 1). 


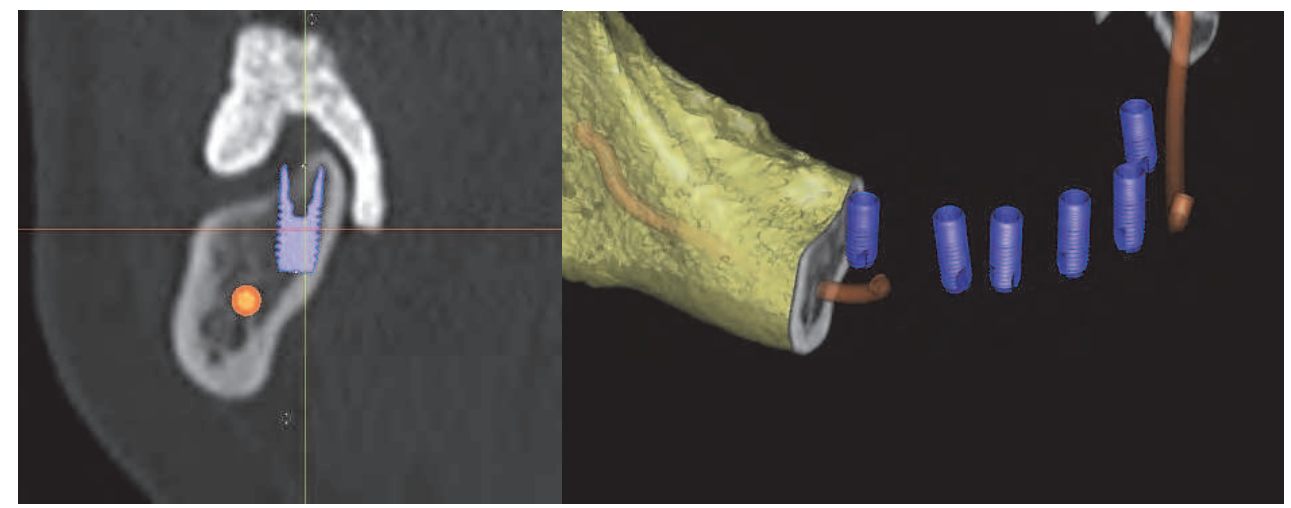

Fig. 1. Depiction of the mandibular nerve (orange point and line) and the implant body (blue cylinders) on cross sectional images and 3D reconstruction. Enhanced viewing capabilities of some software allow 3D depiction of critical anatomic structures in relation with the truesized implants. The interactive features of the planning software allow $360^{\circ}$ rotation of the planning either collectively or individually.

\subsection{SLA surgical guide manufacture}

Utilization of the virtual implant planning in conjunction with the CT-based surface modelling on the basis of the gray-density values (known as the Hounsfield unit) allows rapid manufacturing of biomodels according to the aforementioned SLA technology (Ganz, 2003). In this respect, the spatial position of the virtually planned implants can be outlined by a surgical guide since implants are basically cylindrical objects inserted after the use of cylindrical drills. Therefore, the "SLA guide" can simply locate the point of drilling by outlying the implants entry point on the virtual planning.

Most often this is done by placing "guide tubes" in the central axis of the planned virtual implant which will guide the direction of the drilling during surgery. Accurate positioning of the drills is maintained by the supporting surrounding material: the CT- or CBCT-derived stereolithographic model. Since all modelling manufacturing process is based on a mathematical process, the process is virtually error-free (fig. 2).
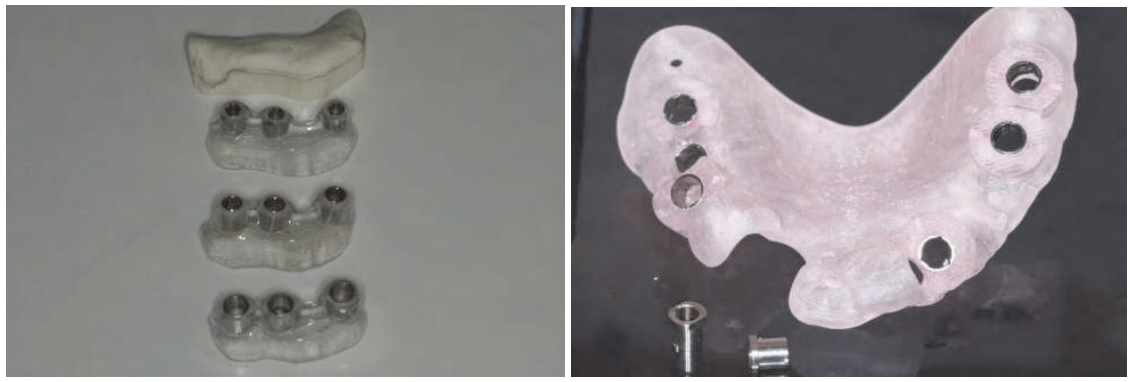

Fig. 2. SLA model (white block) and the multiple-type drill guides with guiding metal sleeves prepared according to the consecutive drill diameters. The guides are replaced after the use of each drill (left). A single-type tooth- and mucosa-suported SLA guide. The drilling is completed via the special metal sleeves (the two-metal tubes located infront of the guide) placed into the guide tubes in the SLA guide (right). 
Since the planning and the production of the SLA guides are realised on the basis of the tomographic data, the reliability and the safety of the whole procedure is mainly dependent on the proper execution of the clinical and radiographic steps revised below.

Most often the placement and restoration of the implants are accomplished by different clinicians usually consisting of a surgeon and a restorative dentist. The surgeon places the implant where the alveolar bone is abundant whereas restorative dentist would prefer proper alignment of the implants according to the emergence profile and root eminence of the prosthesis. In fact, the disregard of the prosthetic conformity in the placement of dental implants usually compromise aesthetic, phonetic, prosthetic and periodontal outcome. For instance, interproximal emergence of the implant between the two teeth implants is one of the most frequently encountered positioning error in implant dentistry. This incidence not only causes an unpleasant aesthetic appearance (especially in cases with high smile line) but also seriously complicates the ability of patients' access to peri-implant area for daily hygiene procedures (Fig. 3).
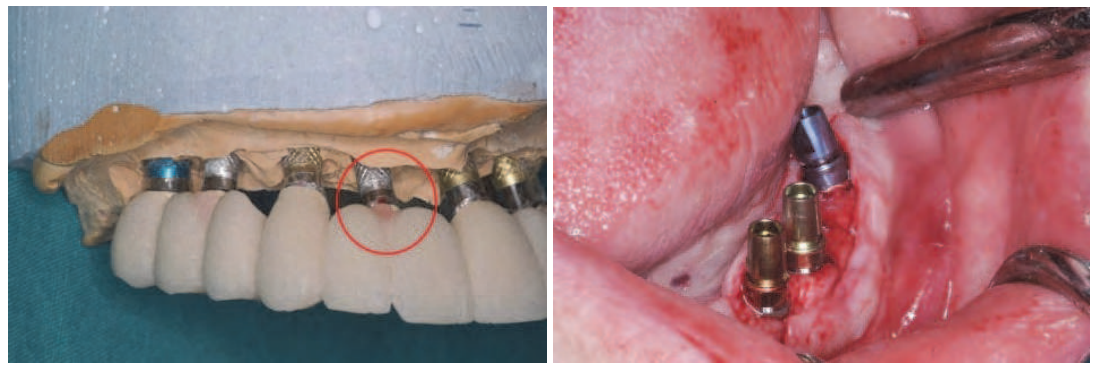

Fig. 3. The emergence point of the implant invades the inter-proximal area of two neighbouring teeth (left). The posterior implant has been placed with an excessively labial inclination and this will complicate the restorative phase (right).

Among such positioning errors, improper parallelism or excessive angulation of multiple implants can also be regarded highly challenging for the restorative dentist.

\section{Potential pitfalls and sources of error in computer-aided implant planning and surgery using stereolithographic guides}

Although its medical utilization was initiated by the late 1980's, comprehensive use of CT technology incorporating prosthetic data in relation with the implant treatment has been recently introduced by a scanning technique employing a radio-opaque scan prosthesis. The process was, however, not uneventful since the CT technicians were mostly trained for medical purposes. Due to their unfamiliarity with dento-maxillofacial scanning procedure and the dental scan prosthesis, the proper execution of the process was prone to error risk in the imaging stage of the "guided implant treatment" sequence. Furthermore the clinician, patient, radiology technician and the auxiliary personnel (if present) -responsible for the segmentation and preparation of the raw $\mathrm{CT}$ or CBCT data for the implant planning- may cause errors which may unfortunately become apparent in later stages of the treatment sequence. Proper execution of each step in the computer-aided implant planning sequence is therefore mandatory to avoid undesired circumstances. It should also be noted that in case of adverse events or outcomes, the primary responsible and legitimate respondent will 
solely be the clinician and therefore a thorough understanding and control of the possible error sources is of utmost importance for the practising dentist. The errors could be due various reasons; resulting from human error(s) and/or technical flaw(s) of the employed equipment.

\subsection{Possible errors and relevant sources}

The cascade of computer aided implant treatment sequence incorporating the "backwards planning" should start with a tooth setup that will be the representation of the final prosthetic goal. In this manner, the clinician should initially create an articulated diagnostic model to evaluate the maxillo-mandibular relationship as well as with the prosthetic allowance and prosthodontics options. This is usually done with plasters models and a consequent wax setup for the bite registration. The clinical try-ins is similar to that of performed for a total prosthesis consisting of registering the vertical dimension and centric occlusion as well as overjet, overbite and smile line. Then the wax-setup of the final tooth positions should be tried intra-orally for ensuring to achieve an accurate prosthesis in terms of aesthetic, functional and phonetic aspects. In this respect the approval of the patient is also an important and motivating factor for the rest of the steps throughout the "computeraided implant treatment". This step is also a unique opportunity to determine and discuss patient expectations which in some instances may carry unrealistic aspects and non-dental issues such as overall correction of the facial appearance (Fig. 4).

It is also important to notice that the final fixed restoration will not have labial flanges and consequently the labial support. Usually patients expect important relief of the circumferential wrinkles around the lip due to an "inflation effect" from the prosthesis. In such cases, the labial flanges of the scan-prosthesis can be removed in order to better simulate the final facial appearance after completion of the treatment.
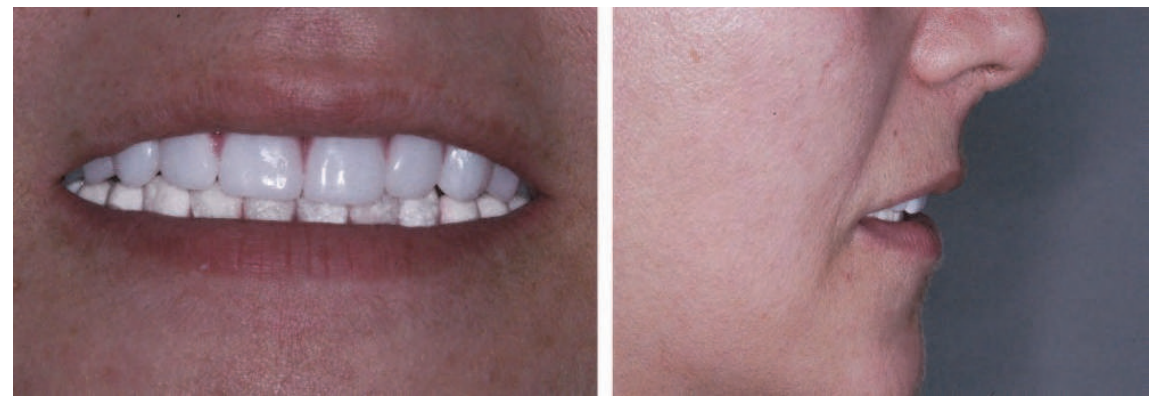

Fig. 4. Try-in of the wax-up dentures representing the final prosthetic goal. Different radioopaque objects were used to prevent interference of upper and lower jaws in the tomographic image. $\mathrm{BaSo}_{4}$-based radio-opaque teeth were used in lower jaw and upper jaw only included a $\mathrm{BaSo}_{4}$-based base (left). The patient should be informed that the final prosthesis will not have the lip-support of the labial flanges (right).

The patient should be able to evaluate and discuss the limitations and consequences of the treatment at this stage. Minor correction of the incisal line and tooth eminence could be performed by the clinician. The resulting phonetics should also be evaluated. A retention medium (i.e, tissue conditioner or prosthesis fixation powder) can be used to hold the prosthesis in the proper position especially if the patient is using the total denture for the 
first time. For such patients it is also important to consider the interference of the scan prosthesis with the healing extraction sockets (if present) and creation of sufficient relief in the impression surface is mandatory to ensure a comfortable fit during the tomographic scan. Usually due to periodontal and/or endodontic disease, the remaining teeth of the patient in the designated jaw have to be extracted prior to the implant surgery. This situation combined with the unfamiliarity of the use of a total prosthesis may lead to serious loss of control regarding the patient holding the prosthesis. Such an incidence is potentially dangerous for the sake of the procedure because the patient is likely to alter the accurate position of the scan prosthesis during tomographic imaging. It should also be noted that an estimated minimum of 2 to 3 weeks which are necessary for the completion of the preoperative stages, will also yield minor soft and hard tissue changes due to extraction-related remodelling.

The clinician should be precautious and should allow prolonged healing periods before the tomographic imaging to ensure that the scan prosthesis is correctly positioned within the patients' mouth. Pain and discomfort during the try-in of the prepared scan prosthesis should be taken as a precaution and the implications of this situation should be explained to the patient. Improper positioning or dislocation of the scan prosthesis during the tomographic scan could be induced by the clinician, patient, radiology technician and the auxiliary post-imaging processor. Some of the most often occurred instances are in table 1.

Errors could be related due to clinician, patient, radiology technician, post-image processing auxiliary personnel. After the tomographic imaging, the preparation and insertion of the implants should be realised without any prolonged time before an additional remodelling occurs in the seating surface of the scan-prosthesis (Table 2).

Besides the errors affecting the scan prosthesis, a number of image artefacts and/or errors can also compromise the quality of the tomographic data (Table 3). Metal scattering is one of the most frequent image artefact in tomography. Ideally, the clinician should remove the metal objects from the mouth prior to the scan as they will introduce serious effects on the resulting image. As a result of the reduced radiation dose the severity of metal scatter (or so known starbust effect) may be less prominent in CBCT. The removal of all possible metallic objects is recommended either in CT or CBCT.

Most likely due to typical daily routines, the CT imaging technician and auxiliary personnel may simply disregard performing key actions for the patient under the computer-aided dental implant treatment sequence. Misalignment of the imaging plane (gantry tilt) is one of the most frequent mistakes made by the CT technicians. In order to facilitate the planning on the cross sectional images, the scan plane should be parallel to the occlusal table identified on the scan prosthesis. Nevertheless the CT technician should be acknowledged regarding the occlusal table - a dentistry related issue-. Arbitrary alignment of the scanning plane may inevitably lead misleading reconstruction and consequent planning as the ideal positioning of the implants is expected to be vertical to the occlusal table. Some planning software incorporate special tools to correct the gantry tilt according to the clinicians' desire. However, such tools may introduce additional errors in CBCT.

\subsection{Segmentation and threshold-processing of CT- and CBCT data}

The aim of this process is to prepare an optimal view of the imaging data including mandible or maxilla, scan prosthesis and existing teeth, if present. Although the tools and processes may differ amongst different software, the basic methodological approach is standard. 


\begin{tabular}{|c|c|}
\hline Respondent & potential sources of error \\
\hline Clinician & $\begin{array}{l}\text {-The clinician may have not sufficiently instructed the patient } \\
\text { regarding the procedure and the role of the scan prosthesis. } \\
\text { - Insufficient healing-time allowed following tooth extraction(s). } \\
\text { - Failure to provide a proper fit of the scan prosthesis to the underlying } \\
\text { mucosa. } \\
\text { - Direct use of existing removable denture without improvements for } \\
\text { the double-scan procedure. } \\
\text { - Insufficient number and/or positioning of the guta markers on the } \\
\text { existing denture in the double-scan procedure. } \\
\text { - Poor result in the duplication of the existing prosthesis. } \\
\text { - Absence of a bite-index }\end{array}$ \\
\hline Patient & $\begin{array}{l}\text { - Patient is unaware of the importance of sustaining the proper } \\
\text { position of the scan prosthesis. } \\
\text { - Gag reflex. } \\
\text { - First time use of a removable denture } \\
\text { - Pain due to irritation of the scan prosthesis to the recent extraction } \\
\text { sockets. }\end{array}$ \\
\hline $\begin{array}{l}\text { Radiology } \\
\text { Technician }\end{array}$ & $\begin{array}{l}\text { - Technician is unaware of the "guided implant surgery" procedure } \\
\text { and the role of the scan prosthesis, failed to provide the appropriate } \\
\text { bite-position index prior to scan }\end{array}$ \\
\hline $\begin{array}{l}\text { Post- } \\
\text { tomographic } \\
\text { image } \\
\text { processing } \\
\text { auxiliary } \\
\text { personnel }\end{array}$ & $\begin{array}{l}\text { - Auxiliary personnel is not trained in "jaw and scan prosthesis } \\
\text { matching" procedure. }\end{array}$ \\
\hline
\end{tabular}

Table 1. Potential error sources and relevant respondents in case of improperly placed scanprosthesis observed in the tomographic images. 


\begin{tabular}{|l|l|}
\hline Respondent & Potential source of error \\
\hline Clinician & $\begin{array}{l}\text { - The clinician may have not sufficiently instructed the patient } \\
\text { regarding the procedure and the role of the scan prosthesis. } \\
\text { - Auxilary personnel (or radiology technician) is unaware of the } \\
\text { need of a scan prosthesis for the procedure. }\end{array}$ \\
\hline Patient & $\begin{array}{l}\text { - Patient forgot or refrained wearing the scan prosthesis. } \\
\text {-Patient assumed to achieve a better result by complying the "well- } \\
\text { known" tomographic principle: "removal of possible objects during } \\
\text { scan". }\end{array}$ \\
\hline $\begin{array}{l}\text { Radiology } \\
\text { Technician }\end{array}$ & $\begin{array}{l}\text {-Technician intentionally removed the scan prosthesis and unaware } \\
\text { of the "guided implant surgery" procedure and the role of the scan } \\
\text { prosthesis. }\end{array}$ \\
\hline $\begin{array}{l}\text { Post-tomographic } \\
\text { image processing } \\
\text { auxiliary } \\
\text { personnel }\end{array}$ & $\begin{array}{l}\text {-Auxiliary is unaware of the double-scan procedure and omitted } \\
\text { "scan-prosthesis" data. } \\
\text {-Gray-density thresholds were not properly adjusted. } \\
\text {-Variant nature of the gray-density values in CBCT was not } \\
\text { emphasized by the auxiliary. }\end{array}$ \\
\hline
\end{tabular}

Table 2. Potential error sources and relevant respondents when the scan prosthesis was found unpresent in the planning data.

Usually, an auxiliary personnel who is trained in this step performs this time-consuming process. Initially the gray-density values are adjusted according to relevant density levels of the bone, scan prosthesis and remaining teeth if present. This is rather tricky in CBCT since the gray-density values are not absolute and may need precise manual adjustment to fully visualize intact 3D structures in the software. Due to standard distribution of the HU in the $\mathrm{CT}$, segmentation according to the pre-determined $\mathrm{HU}$ values usually reveals satisfactory results. As compared to the $\mathrm{CT}$, the $\mathrm{CBCT}$ images also include higher radiographic "noise" which requires manual removal prior to the planning. The use of CBCT however is advantageous in the presence of the metallic objects in the mouth. The intensity of the metalscattering (or starbust) effect is significantly reduced with the lower exposure of CBCT. The quality of the segmentation procedure will ease the planning of implants by providing clear visibility in the constructed $3 \mathrm{D}$ model.

\section{Dental implant planning on cross-sectional images}

The modification of the recently available medical 3D examination and planning software has led to the introduction of various "dental implant planning" software in the market. The majority of these software simply make use of well-known re-formatting algorithms to 


\begin{tabular}{|c|c|c|c|c|c|}
\hline \begin{tabular}{|l|} 
Image \\
artefact/ error
\end{tabular} & $\begin{array}{l}\text { Clinician- } \\
\text { related }\end{array}$ & $\begin{array}{l}\text { Patient- } \\
\text { related }\end{array}$ & $\begin{array}{l}\text { Radiology } \\
\text { technician-related }\end{array}$ & $\begin{array}{l}\text { Post-scan processing } \\
\text { auxiliary technician- } \\
\text { related }\end{array}$ & Effects \\
\hline $\begin{array}{l}\text { Heavy } \\
\text { scattering } \\
\text { (Starbust } \\
\text { effect). }\end{array}$ & $\begin{array}{l}\text {-Failed to } \\
\text { remove } \\
\text { metal- } \\
\text { containing } \\
\text { restorations } \\
\text { prior to the } \\
\text { scan }\end{array}$ & $\begin{array}{l}\text {-Forgot } \\
\text { removing } \\
\text { opposing } \\
\text { denture } \\
\text { including } \\
\text { metallic } \\
\text { components. }\end{array}$ & $\begin{array}{l}\text {-Failed to adjust } \\
\text { exposure } \\
\text { parameters to } \\
\text { reduce scattering. }\end{array}$ & $\begin{array}{l}\text {-Failed manual } \\
\text { removal of scattering } \\
\text { objects from the 3D } \\
\text { rendering }\end{array}$ & $\begin{array}{l}\text { Mostly } \\
\text { CT } \\
\text { Also } \\
\text { CBCT }\end{array}$ \\
\hline Blurred image & none & $\begin{array}{l}\text {-Patient } \\
\text { moved } \\
\text { during } \\
\text { scanning } \\
\text {-Gag reflex } \\
\text {-Failure to } \\
\text { keep still due } \\
\text { to anxiety. }\end{array}$ & \begin{tabular}{|l|}
-Technician failed to \\
notify patient to \\
hold still during \\
scan. \\
-Technician did not \\
checked the \\
resulting images or \\
unaware of the \\
dento-facial \\
imaging.
\end{tabular} & none & $\begin{array}{l}\text { Mostly } \\
\text { CT } \\
\text { Also } \\
\text { CBCT }\end{array}$ \\
\hline $\begin{array}{l}\text { Improper } \\
\text { gantry tilt }\end{array}$ & $\begin{array}{l}\text { - Failure to } \\
\text { provide } \\
\text { sufficient } \\
\text { information } \\
\text { to the } \\
\text { radiology } \\
\text { technician }\end{array}$ & None & $\begin{array}{l}\text { Technician is } \\
\text { unaware of the } \\
\text { guided-surgery } \\
\text { imaging procedure. }\end{array}$ & $\begin{array}{l}\text {-Auxilary did not } \\
\text { corrected the tilt of the } \\
\text { images during post- } \\
\text { tomography } \\
\text { processing }\end{array}$ & $\begin{array}{l}\text { CT and } \\
\text { CBCT }\end{array}$ \\
\hline $\begin{array}{l}\text { Impartial } \\
\text { structures in } \\
\text { the 3D model }\end{array}$ & None & None & $\begin{array}{l}\text { CBCT technician } \\
\text { may have not } \\
\text { provided sufficient } \\
\text { current (radiation } \\
\text { dose or duration) } \\
\text { for the procedure }\end{array}$ & $\begin{array}{l}\text {-Threshold values } \\
\text { were improperly } \\
\text { adjusted. } \\
\text {-Segmentation process } \\
\text { was poor. } \\
\text { - Auxiliary is } \\
\text { unaware of the } \\
\text { variant } \\
\text { gray-density values } \\
\text { in CBCT. }\end{array}$ & $\begin{array}{l}\text { Mostly } \\
\text { CBCT } \\
\text { Also CT }\end{array}$ \\
\hline
\end{tabular}

Table 3. Possible artifacts/errors on $\mathrm{CT}$ and $\mathrm{CBCT}$ images and relevant sources. 
provide cross-section views of any desired area. Also a 3D reconstruction accompanies the planning steps by providing better visualisation and thorough understanding of the complete intervention including implant-prosthesis relationship. The implants are generally constructed and modelled by basic cylinders of varying length and diameter. Some software additionally incorporates realistic implant shapes and abutments of commercially available dental implants as well. The panning and zooming of the reconstructed 3D model significantly enhances the quality of the planning and assures the accuracy of the final outcome. The clinician should practice and emphasize the use of these features of the implant planning software before starting to treat patients with this method.

\subsection{Determinaiton of the "panoramic line" relevant cross-sections}

Initially, a guide line (called as panoramic line), along the body of the alveolar crest has to be marked by the clinician. Connected by a group of points marked by the clinician, the software calculates re-formatted images along the route of this line and displays axial, sagittal and frontal views in relevant windows. On these views, the clinician is able to see critical anatomy, the inferior and superior borders of the jaw and the scan prosthesis. By using the navigation options on the software, the clinician may "explore" the best possible location for the implant regarding the scan-prosthesis and the patients' jaw anatomy. All cross-sectional views as well as the 3D construction simultaneously interact with the response of the planning clinician (Fig. 5).

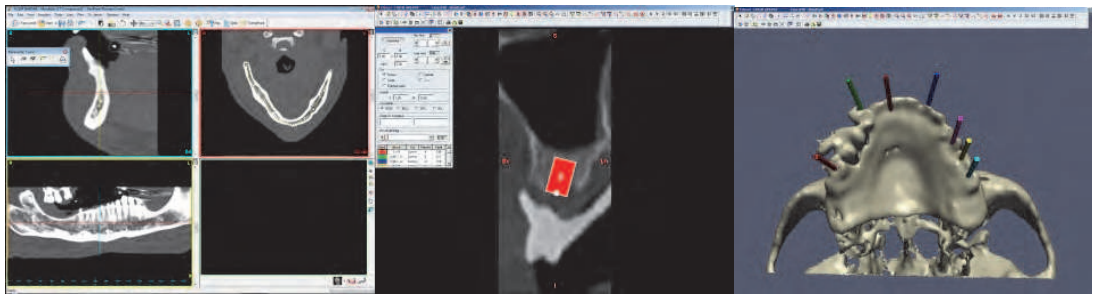

Fig. 5. Marking of the panoramic line should center the available alveolar bone width (left).

The virtual implant (red rectangle) planned in relation with the scan prosthesis on the reformatted cross-sectional image (middle) simultaneously interacts with the 3D model (right).

\subsection{Depiction of important anatomic structures}

Proper identification of the critical anatomy relevant to the implant insertion surgery is one of the most beneficial advantages of SLA-guided surgery. By means of dedicated tools in the software, the clinician may outline mandibular nerve ( $n$. alveolaris inferior), the foramens (foramen mentalis) as well as the maxillary structures such as sinuses (sinus maxillaris) and nasal base (vomer). Using the navigation feature on the cross-sectional images the clinician can mark these important anatomies as bright-coloured 3D structures which are also displayed on the $3 \mathrm{D}$ view window. The automated collision detectors of the software will warn the clinician in case of an approximation and/or collision with any of the marked structures.

\subsection{Planning a virtual implant}

After ensuring the best possible location of an implant the clinician may select from a variety of available virtual implants and place on any of the axial, sagittal or frontal views. 
Then the length and the diameter of the implant can be adjusted according to the available bone volume. The use of the reconstructed 3D model is especially useful in the alignment of the proper implant angulation in accordance with the scan prosthesis. This procedure is rather easy if guide holes have been previously drilled on the scan prosthesis. Also, enhanced viewing capabilities of some software which allows "toggling" the view of implant, bone and the scan prosthesis either collectively or individually, may significantly improve the accuracy of virtual planning (Fig. 6).
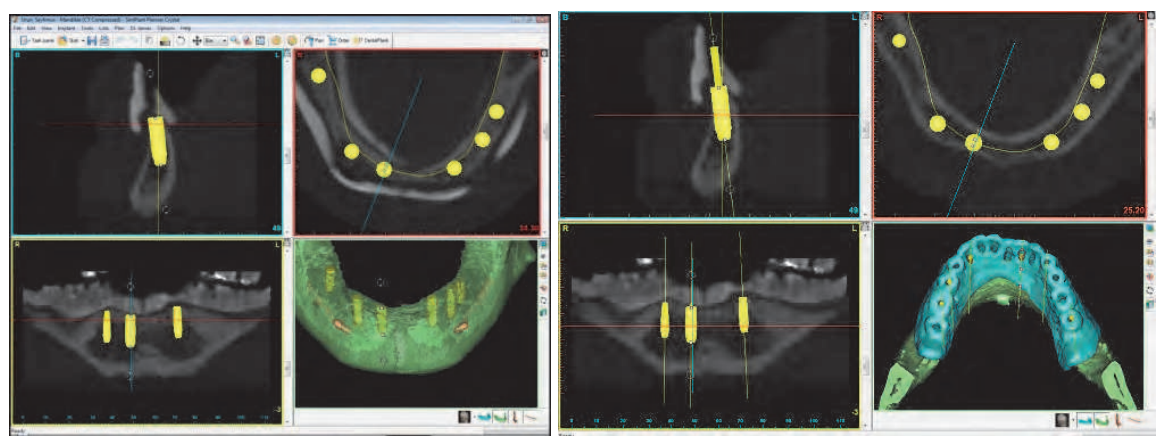

Fig. 6. The view of jaw bone, implants and the scan prosthesis can be visualized collectively (right) or individually (left).

\subsection{Planning the fixation of the guide}

The rigidity of the guide during osteotomy is essential for ensuring the accurate transfer of the virtual implant positions into the patients' mouth. Especially in totally edentulous cases, the guide is likely to tilt and move during the procedure. Patients" movement, clinicians' posture and frictional resistance between the tubes and the drills can be regarded as potentially intruding during the surgery. In a previous study it was demonstrated that the use of 3 or more fixation screws decrease the transfer-error of implants placed by SLA guides (Arisan et al., 2010b).

If a solely mucosa-supported guide is planned for the case, incorporation of rigid fixation by means of osteosynthesis screws, pins etc. is essential. In tooth- and bone- supported guides this is not mandatory and depends on the clinicians' decision. Author suggests incorporation of fixation screws for all guides at the stage of virtual planning. By doing so, the manufacturer will incorporate dedicated guide holes with the exact dimensions of the fixation element. To prevent tilting and dislocation of the SLA guide during screwing (or insertion), fixation elements should be planned with a $45^{\circ}$ angle to the horizontal plane. Manual access to the planned fixation elements should be predetermined carefully, since screws planned too apical or distal may not be managed within the patients' mouth (Fig. 7).

\subsection{Deciding the type and the support type of the SLA guide}

The basic role of the SLA guides is to control the direction of the implants during the osteotomy. To do so, a guide cylinder in comply with the drill diameter, is embedded into the guide. Initial use of this method was involved with multiple guides (Fig 2). Formerly, SLA guides usually consisted of multiple guides which were replaced after each use. This is of course clinically impractical and was shown to be increasing the deviations of the placed implants in comparison to the planned implants (Arisan et al., 2010b). 

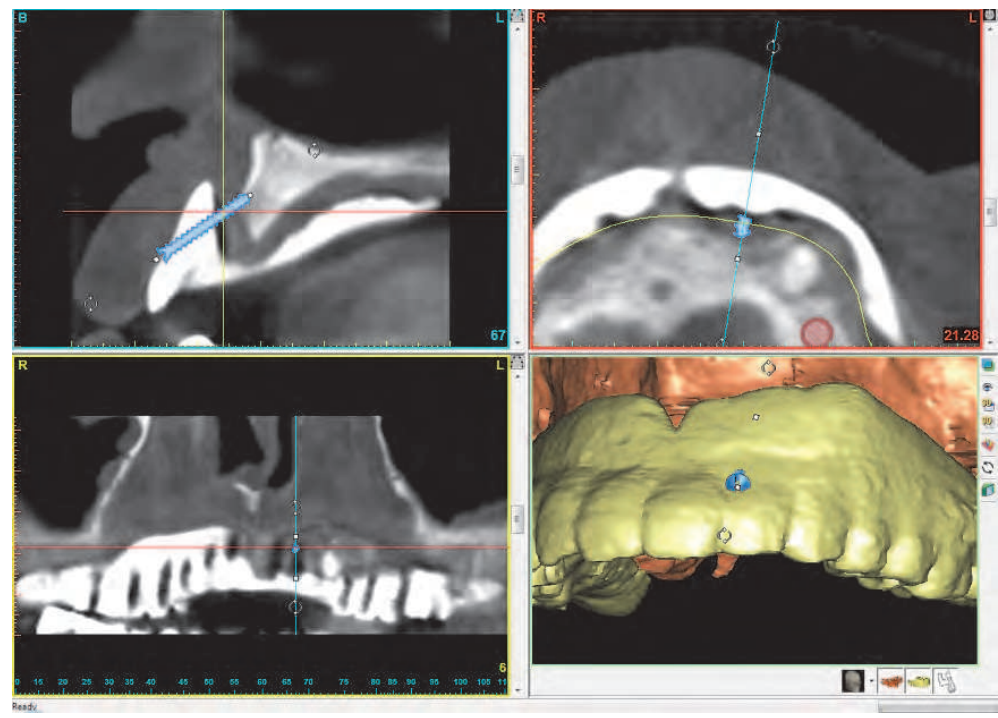

Fig. 7. To avoid shifting of the SLA guide, the fixation screws should be planned with a $45^{\circ}$ angle to the horizontal plane.

At the stage of computer-planning, the clinician should also decide the type of support for the SLA guide. Thorough evaluation of the patients jaw characteristics is crucial when deciding the support type. It should be noted that jaws exhibiting insufficient alveolar bone thickness to accommodate the designated implant diameter have to be operated by additional augmentative procedures following a flap exposure. Basically the SLA guides can be seated on the alveolar bone, existing tooth and the mucosa. The production of bone and tooth supported SLA guides are independent of a scan prosthesis. For a mucosa-supported SLA guide, CT/CBCT imaging of the patient with perfectly fitting scan-prosthesis (the impression surface) is essential since the seating surface of the SLA guide will be an modified replicate of the involved scan prosthesis.

\subsubsection{Mucosa support}

Using a mucosa-supported guide the clinician may execute a flapless surgery by just removing the circular tissue over the implants by a special guided mucotome and a drill-kit with depth controlling physical stoppers. By doing so, the surgical duration as well as with the postoperative complications may significantly diminish (Arisan et al., 2010a). For performing a "flapless surgery", the alveolar bone receiving the implant body should be wide enough to accommodate a narrow-diameter (usually between 3.00 to $3.50 \mathrm{~mm}$ ) implant. It is known that, a minimum of $1 \mathrm{~mm}$ bone thickness should cover the implant for ensuring long-term survival. Therefore the clinician should seek for sufficient bone thickness when considering a flapless implant surgery for the patient. If any of the planned implant sites reveals a bone thickness below 1-mm in the lingual or buccal aspect of the virtual implant, clinician should consider the need of flap exposure for augmentation procedures.

In such cases, the support type can be bone or teeth (if present) or even mucosa which requires an incision for bone exposure. Alternatively, a bone calliper can be used to measure 
the local bone thickness under infiltrative anaesthesia. By doing so, patients exhibiting severe bone atrophy can be determined and if a fixed metal-ceramic prosthesis is not an option, the patient could be sent straight to tomographic imaging without a scan prosthesis. Because the prosthetic conformity of the implants would not be that critical in cases where gross amount of bone is missing.

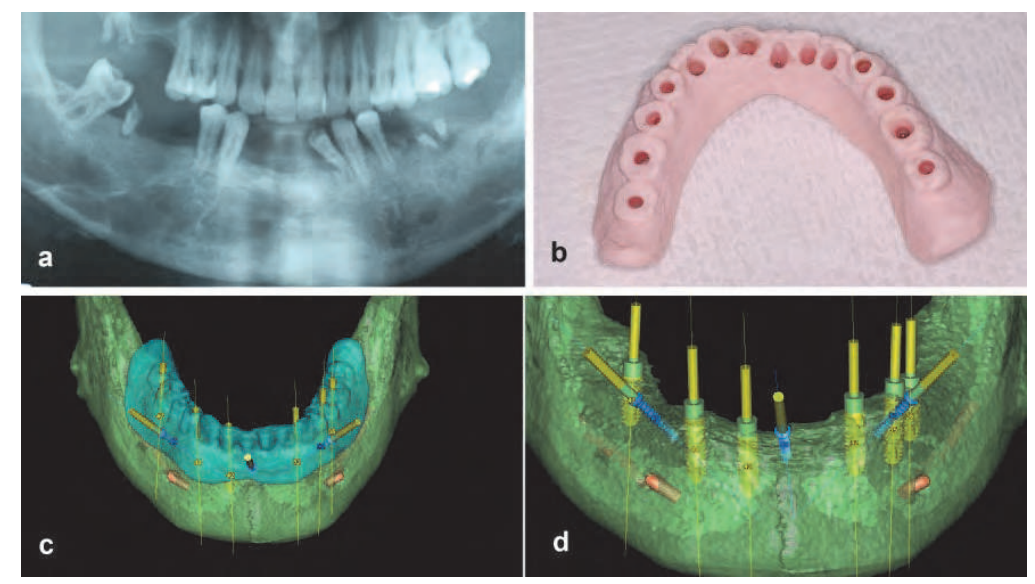

Fig. 8. a) Panoramic x-ray of the patient exhibit progressed decay and periodontal disease, b) a radiopaque scan prosthesis is prepared with guide holes to facilitate planning, c ) implants were planned in relation with the scan prosthesis, $d$ ) planned implants are fully embedded into the alveolar bone and there is no need of bone augmentation.

If all of the planned implants are surrounded by a minimum of 1-mm bone, the clinician may consider executing the implant surgery without raising a flap. Delicate oral mucosa may wrap around the mucotome and drills during osteotomy and the patient may get injured. This is an additional point of concern in deciding "flapless implant surgery" using the support of mucosa. A minimum of $5 \mathrm{~mm}$ attached mucosa should therefore be sought on the designated implant site for ensuring the safety of the procedure. Though not generalizable, it can be claimed that the percentage of patients suitable for a mucosasupported flapless implant surgery would be relatively small compared to bone- or tooth support. However, due to lack of incision and suturing (flapless implant surgery), the comfort of the patient can significantly be enhanced during surgery and in the postoperative period (Fig. 8); (Arisan et al., 2010a).

\subsubsection{Tooth support}

Healthy tooth can be used to support the SLA guide during surgery. By matching the stereolithographic implant planning data and the laser scan model of the patients' mouth (by a plaster model) a very precise fit can be assured. In the majority of the available dental literature, the tooth supported SLA guides were shown to be superior to other types of SLA guides in terms of minimizing the transfer error from the planning due to the stiff support of the teeth. This is, however, mainly dependent on the number and the rigidity of the existing teeth. It is of no doubt that the rigidity of the tooth-supported SLA guide will dramatically differ if the SLA guide is supported by a couple of periodontally compromised 


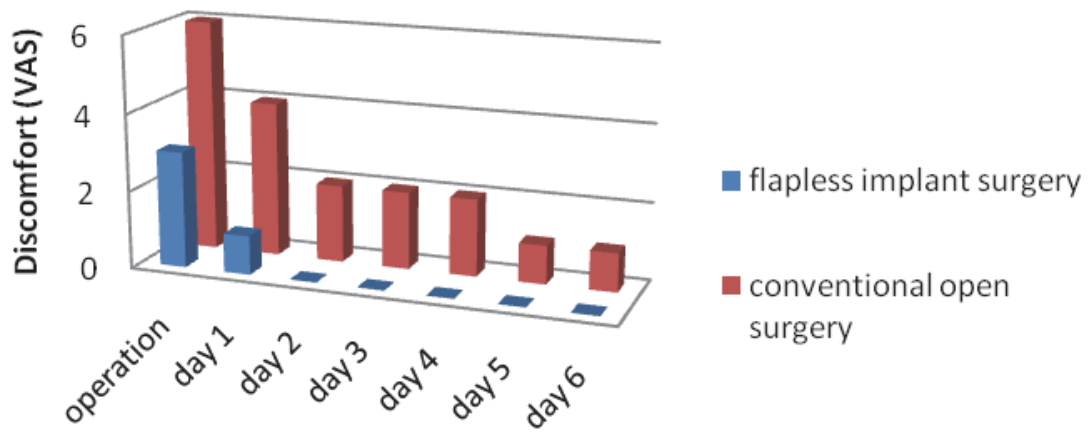

Fig. 9. Discomfort scores of patients in the week after treated by conventional implant and flapless implant surgery techniques (Visual analog scale: 0:no discomfort, 10: extremely high discomfort.).

teeth in a uni-lateral position. Heavily rotated or super-erupted teeth should also be avoided due to the presence of undercuts. The use of teeth support for the SLA guide seems feasible especially in the presence neighbouring teeth in the distal and mesial aspect of the designated implant area.

\subsubsection{Bone support}

Bone-support is the basic type of support in SLA-guided implant surgery and can be used in any cases irrespective of the aforementioned criteria regarding mucosa and tooth support. Simply by placing the SLA guide on the alveolar bone tissue, the osteotomy can be completed. Some clinicians prefer to use this type of support for just marking the beginning point of drilling and then continue the osteotomy and additional procedures (i.e. augmentation, bone splitting, sinus lifting) if required. Bone-supported SLA guides require additional extension of the flap borders than normal because the edges of the SLA guide may interfere with the soft tissue and hamper proper fit. This is of particular importance if multiple guides are used during the surgery as the edge of the flap may relapse under the SLA guide while switching to another guide. Amongst other type of SLA guides, bonesupported guides have the highest number of available scientific documentation.

The following diagram can be used in the consideration of support type. Nevertheless, special circumstances of each individual case should always be respected.

The final data could be sent to the production facility and usually the SLA guide can be retrieved within 2 weeks.

\section{Surgical phase}

The retrieved SLA guide should be checked for possible errors. The seating (or impression) surface may contain minor porous particles and may cause discomfort of the patient. Such sharp edges and irregularities should be carefully removed by proper tools. Also it is important to check the operability of the surgical hand piece on the SLA guide as some hand piece instruments may have large connections or rotational parts interfering with the SLA guide. In such cases, an alternative handpiece should be considered. Following these steps the patient must be re-examined to check the proper fit of the SLA guide when mucosa 
$<5 \mathrm{~mm}$; possible soft tissue problems \& use of mucotomes are not indicated : Bone-or teeth-supported SL.A guides $>5 \mathrm{~mm}$; the use of mucotomes are possible: Flapless implant surgery via mucosa-supported SLA guides

Alveoler bone width

<implant diamater $+2 \mathrm{~mm}$; possible need of bone augmentation \& flap exposure: Bone -or teeth- supported SLA guides

>implant diamater $+2 \mathrm{~mm}$; no need of bone augmentation \& flap exposure: Flapless implant surgery via mucosa supported SLA guides

Fig. 10. Schematic representation of the criteria that should be considered in deciding the SLA guides' support type. The clinician should use transversal, sagittal and frontal crosssections in relation with the intra-oral records (intra-oral photographs, bone-thickness measurements via bone-calliper and plaster models) of the patient. The need of possible bone augmentation should be evaluated for each planned implant.

and/or tooth support is used. Care should be given to ensure the accurate fit of the guide and a bite-index should be obtained to repeat the accurate SLA guide position in surgery. Additional steps can also be undertaken in this step if an immediate loading protocol is planned for the patient. By using any of the available technologies such as CAD/CAM design\& manufacture or SLA-based laboratory modelling, an interim prosthesis can be fabricated prior to the surgery.

\subsection{Implant surgery via CT- or CBCT-derived SLA guides}

The surgical tray and related armamentarium should be made available in the surgical theatre. Alternatively, the equipment for the conventional surgical sequence should be ready in case of an adverse event involving the SLA guide and relevant instruments. The drilling sequence and the implants to be inserted (planned on the software) should also be prepared in a concise manner to prevent unnecessary confusion during the surgery. Some manufacturers provide a printed list of drills and implants with exact length and diameter information whereas others expect this to be listed by the clinician particularly. If a special osteotomy kit is to be used in the surgery, the relevant components and handles (or so called "spoons") should be examined before the surgery. The insertion of implants is also guided via the guided-fixture-mounts in some systems. To facilitate the surgery, guided-fixturemounts could be connected on top of implants and could be laid-out in the proper order on the special surgical tray. With such setup, the clinician would not get confused in sustaining the right order of the implants during insertion (Fig 11). 


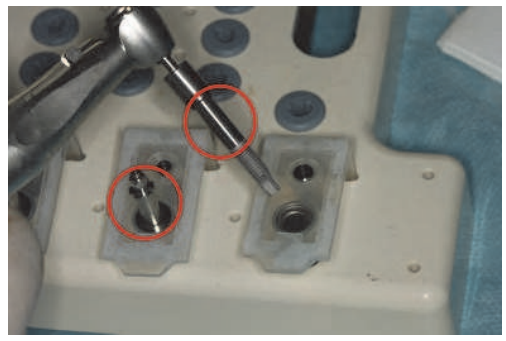

Fig. 11. Guided implant mounts (encircled by red) connected to the implants which were laid onto the special surgical tray in the right order.

The exact replication of the accurate positioning of the SLA guide as it was during the tomographic scan is of utmost importance for ensuring the accuracy of the implants placed by mucosa-supported guides. To do so, the bite-index obtained in the previous examination is extremely convenient. Using this index, the clinician should position the guide properly. Swelling of the mucosa after infiltrative anaesthesia may slightly alter the position of the mucosa-supported SLA guide. Therefore, anaesthetic administration through the holes of the SLA guide while the guide is in occlusion with the antagonist jaw may be beneficial in terms of preventing the shifting of the SLA guide. The diffusion of the anaesthetic liquid will be slower than normal and the clinician should allocate an extended amount of time for the anaesthesia. In tooth-supported guides, the process can be accomplished as usual if there is no interaction of the guide with the mucosa.

Care should be given to ensure that the bone-supported guide seats properly on the alveolar bone surface. When multiple-type SLA guides are used, the clinician must ensure proper fit of all consecutive guides throughout the osteotomy.

If fixation screws were planned (on single-type guides only), they should be screwed while the guide is in occlusion with the antagonist jaw. When fixing the SLA guide to the underlying bone, all screws should be initially screwed to the end, but the final tightening of each screw should be realised simultaneously as possible. Because tightening just one screw to the end at once may provoke shifting of the guide towards the direction of the screw. Also the tightness of these screws should be checked frequently during the osteotomy because the drilling forces may loosen these screws and may induce deviations.

\subsubsection{Risk of over-heating}

A non-traumatic surgery is essential for ensuring the osseointegration process of dental implants. Since the osteotomy is performed in a closed manner through the guide sleeve holes on the SLA guide, abundant irrigation of the osteotomy area is critical to prevent overheating. The surgeon must be aware of this risk and control the osteotomy procedure with precaution. The operational rpm of the surgical motor should be reduced. An auxillary irrigation source can also be utilized. Another option is to chill the irrigation solution before the surgery. Prolonged periods of drilling should be avoided while the drill is fully inserted into the tube. Frictional resistance will reveal itself by a metallic sound during drilling and must be regarded as an incator of heat generation. To prevent this, the surgeon must check and initiate the drilling in parallel to the axis of each guide cylinder. If the SLA guide provides depth-control of the osteotomy, the surgeon can 
realize the process by a simple in-and -out motion. This is particularly useful in flapless surgeries. If no depth control is provided, then the surgeon must check the exact osteotomy depth visually. This may constitute an important amount of time in cases where multiple numbers of implants are simultaneously placed. Copious irrigation of the osteotomy hole may help removal of debris prior to the insertion of implants. The clinician may insert the implants manually (following the removal of the SLA guide) if the SLA guide provides no guided-implant-insertion (Fig. 12).
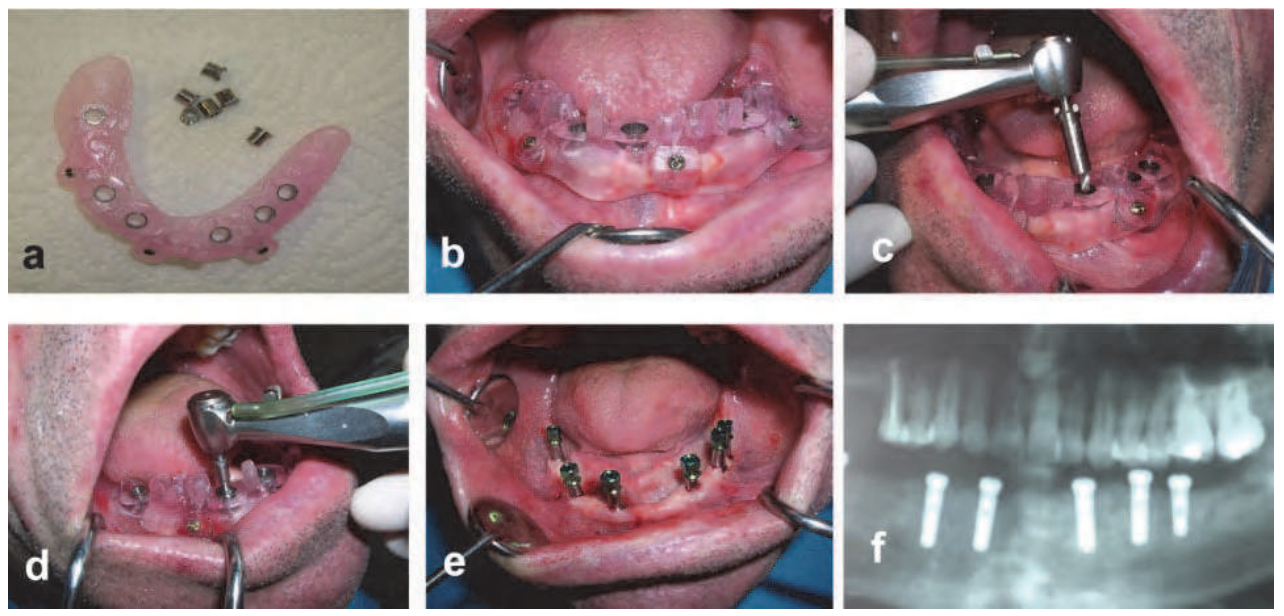

Fig. 12. a) Single-type mucosa-supported SLA guide and corresponding guiding sleeves, b) the guide is firmly fixed via three osteosythesis screws, c) a special guided-mucotome was used to remove the mucosa over the implant recipient areas, d) the guiding seleeves were mounted on the tubes of the SLA guide and osteotomy was completed with the special drill which controlled the depth of the osteotomy, e) clinical view after the insertion of 6 implants, f) post-operative radiographic view exhibits uneventful placement of 6 implants.

\subsection{Guided implant insertion}

Some SLA-guide systems provide guided implant insertion via the guided implant mounts provided in the special surgical kit. The length and the diameter of these implant mounts differ according to the planned implants' length and placement level and therefore the clinician must assure the correct choice of implant mounts. Guided-implantmounts with a mismatching diameter may simply not fit into the guide tube (or will stay loose in the tube) during insertion. Similarly, an incorrect guided-implant-mount length either will not let full insertion of the mount into the tube or will leave implants partially inserted into the alveolar bone.

For the insertion of implants, the surgeon may use a torque-controlled surgical motor or may manually screw the implants using the hand-ratchet provided in the surgical tray. If the insertion of implants is to be realised through the SLA guide, the surgeon may utilize the "tripodial" placement approach to prevent the tilting of the guide. Placement of posterior implants followed by an implant in the anterior aspect will provide the "tripodial" position and prevent tilting of the SLA guide. As long as a minimum of three tripodial implants support the SLA guide, one of the implants in these positions could be removed after the 
insertion of neighbouring implants. Consecutive insertion of all implants without removal of any mounts may cause undesired tightening of the implant mounts and complicate the removal of mounts.

After insertion of all implants, the mounts are unscrewed and carefully removed. Following the removal of the SLA guide the implants can be checked for primary stability- a critical perquisite for assuring osseointegration (Abdel-Haq et al., 2011). Implants posing a risk of insufficient primary stability can be predetermined on the planning stage according to the gray-density values. Usually, implants placed in a bone with a gray-density value of below 250HU may yield insufficient stability upon insertion (Shapurian et al., 2006). Nevertheless, primary stability also depends on the macroscopic design of the implant body.

The clinician may decide to leave implants to "submerged" or "non-submerged" healing according to the specific conditions of the case. Additionally procedures such as bone augmentation could be performed followed by the flap repositioning and suturing. If the surgery is completed without a flap exposure, the healing caps could be screwed and the additional second stage surgery (for exposing the implants) can be eliminated.

\section{Conclusion}

The field of Implant Dentistry, Oral and Maxillofacial Surgery and relevant oral surgery disciplines have been recently adapted 3D imaging and virtual planning which can be regarded as performing a virtual surgery in advance of the actual intervention. Up until now, the use of 3D tomographic imaging was more common in the medical community. However, the emerging of more affordable and maintainable cone-beam tomographic scanners enabled dental professionals to provide treatment-specific planning especially for cases requiring implant insertion. Implementation of dedicated implant software the guesswork of where, which implant fixture and how to firmly place an implant is potentially eliminated.

Since implant dentistry is a matter of life quality rather than life necessity, alleviation of the discomfort throughout the treatment sequence may significantly improve the acceptance and the appreciation of the candidate patient. It is of no doubt that the technology will continue its rapid evolution delivering more efficient tools to the professionals aiming to provide better standard of care for the edentulous patient.

\section{Acknowledgments}

Author would like to thank Prof.Dr. Cüneyt Karabuda, Prof.Dr. Tayfun Özdemir, Assoc.Prof.Dr. Selim Ersanlı and Prof. Dr. Serdar Yalçın from the Department of Oral Implantology, Faculty of Dentistry, Istanbul University for their support. The charity and help of collaborating colleagues in the same department and assistance of Ms. Ayca Kabaoglu is also gratefully acknowledged. Last but not least author thanks Istanbul University Research Fund for the generous support.

\section{References}

Abdel-Haq, J., Karabuda, C., Arisan, V., Mutlu, Z. \& Kurkcu, M. (2011) Osseointegration and Stability of a Modified Sand-Blasted Acid-Etched Implant: an Experimental Pilot 
Study in Sheep. Clinical Oral Implants Research, Vol.22, No.3 (March 2011), pp.265274, ISSN 0905-7161.

Akca, K., Iplikcioglu, H. \& Cehreli, M. C. (2002) A surgical guide for accurate mesiodistal paralleling of implants in the posterior edentulous mandible. Journal of Prosthetic Dentistry, Vol.87, No.2, (Febryaury 2000), pp.233-235, ISSN 0022-3913.

Amet, E. M. \& Ganz, S. D. (1997) Implant treatment planning using a patient acceptance prosthesis, radiographic record base, and surgical template. Part 1: Presurgical phase. Implant Dentistry, Vol.6, No.3, (Fall 1996), pp.193-197, ISSN 10566163.

Arai, Y., Tammisalo, E., Iwai, K., Hashimoto, K. \& Shinoda, K. (1999) Development of a compact computed tomographic apparatus for dental use. Dento-Maxillo-Facial Radiology, Vol.28, No.4, (July 1998), pp.245-248, ISSN 0250-832X.

Araki, K., Maki, K., Seki, K., Sakamaki, K., Harata, Y., Sakaino, R., Okano, T. \& Seo, K. (2004) Characteristics of a newly developed dentomaxillofacial $X$-ray cone beam CT scanner (CB MercuRay): system configuration and physical properties. Dento-Maxillo-Facial Radiology, Vol.33, No.1, (January 2002), pp.51-59, ISSN 0250$832 X$.

Arisan, V., Karabuda, C. Z. \& Ozdemir, T. (2010a) Implant surgery using bone- and mucosa-supported stereolithographic guides in totally edentulous jaws: surgical and post-operative outcomes of computer-aided vs. standard techniques. Clinical Oral Implants Research, Vol.21, No.9, (September 2010), pp.980-988, ISSN 09057161.

Arisan, V., Karabuda, Z. C. \& Ozdemir, T. (2010b) Accuracy of two stereolithographic guide systems for computer-aided implant placement: a computed tomography-based clinical comparative study. Journal of Periodontology, Vol.81, No.1, (January 2010), pp.43-51, ISSN 1600-0765.

Asberg, B., Blanco, B., Bose, J., Garcia-Lopez, M., Overmars, G., Toussaint, G. \& Wilfong, B. (1997) Feasibility of design in stereolithography. Algorithmica, Vol.19 (Special Issue on Computational Geometry in Manufacturing), No.1/2, (January 1997), pp.61-83, ISSN 0302-9743.

Baba, R., Konno, Y., Ueda, K. \& Ikeda, S. (2002) Comparison of flat-panel detector and image-intensifier detector for cone-beam CT. Computerized Medical Imaging and Graphics, Vol.26, No.3, (May-June 2002), pp.153-158, ISSN 0895-6111.

Basten, C. H. (1995) The use of radiopaque templates for predictable implant placement. Quintessence International, Vol.26, No.9, (September 1995), pp.609-612, ISSN 00336572.

Basten, C. H. \& Kois, J. C. (1996) The use of barium sulfate for implant templates. Journal of Prosthetic Dentistry, Vol.76, No.4, (October 1996), pp.451-454, ISSN 0022-3913.

Belser, U. C., Bernard, J. P. \& Buser, D. (1996) Implant-supported restorations in the anterior region: prosthetic considerations. Practical Periodontics and Aesthetic Dentistry, Vol.8, No.9, (November-December 1996), pp.875-883; quiz 884, ISSN 1042-2722.

Blanchet, E., Lucchini, J. P., Jenny, R. \& Fortin, T. (2004) An image-guided system based on custom templates: case reports. Clinical Implant Dentistry and Related Research, Vol.6, No.1, (January 2004), pp.40-47, ISSN 1708-8208.

Carrafiello, G., Dizonno, M., Colli, V., Strocchi, S., Pozzi Taubert, S., Leonardi, A., Giorgianni, A., Barresi, M., Macchi, A., Bracchi, E., Conte, L. \& Fugazzola, C. (2010) 
Comparative study of jaws with multislice computed tomography and cone-beam computed tomography. Radiological Medicine, Vol.115, No.4, (June 2010), pp.600611, ISSN 0033-8362.

Ganz, S. D. (2003) Use of stereolithographic models as diagnostic and restorative aids for predictable immediate loading of implants. Practical Periodontics and Aesthetic Dentistry Dentistry, Vol.15, No.10, (November-December 2003), pp.763-771; quiz 772, ISSN 1042-2722.

George, A., Zarb, G. \& Tomas, J. (1985) Tissue- Integrated Prosthesis: Osseointegration in Clinical Dentistry. In: Tissue- Integrated Prosthesis: Osseointegration in Clinical Dentistry, (ed.) P. I. Branemark, Zarb, G, Albrektsson T., pp. 241-282. Quintessence, ISBN 0-86715-129-3, Chicago, USA.

Gotfredsen, K. \& Karlsson, U. (2001) A prospective 5-year study of fixed partial prostheses supported by implants with machined and TiO2-blasted surface. Journal of Prosthodontics, Vol.10, No.1, (March 2001), pp.2-7, ISSN 0893-2174.

Kalpidis, C. D. \& Setayesh, R. M. (2004) Hemorrhaging associated with endosseous implant placement in the anterior mandible: a review of the literature. Journal of Periodontology, Vol.75, No.5, (May 2004), pp.631-645, ISSN 1600-0765.

Katsumata, A., Hirukawa, A., Noujeim, M., Okumura, S., Naitoh, M., Fujishita, M., Ariji, E. \& Langlais, R. P. (2006) Image artifact in dental cone-beam CT. Oral Surgery, Oral Medicine, Oral Pathology, Oral Radiology, and Endodontics, Vol.101, No.5, (May 2006), pp.652-657, ISSN 1079-2104.

Klein, M., Cranin, A. N. \& Sirakian, A. (1993) A computerized tomography (CT) scan appliance for optimal presurgical and preprosthetic planning of the implant patient. Practical Periodontics and Aesthetic Dentistry, Vol.5, No.6, (August 1993), pp.33-39; quiz 39, ISSN 1042-2722.

Lekholm, U., \& Zarb GA. (1985) Patient selection and preperation. In: Tissue-integrated prosthesis, (ed.) P. Branemark, Zarb G, Albrektsson T., pp. 199-209. Quintessence, ISBN 0-86715-129-3, Chicago, USA.

Raghoebar, G. M., Meijer, H. J., Stegenga, B., van't Hof, M. A., van Oort, R. P. \& Vissink, A. (2000) Effectiveness of three treatment modalities for the edentulous mandible. A five-year randomized clinical trial. Clinical Oral Implants Research, Vol.11, No.3, (June 2000), pp.195-201, ISSN 0905-7161.

Reddy, M. S., Mayfield-Donahoo, T., Vanderven, F. J. \& Jeffcoat, M. K. (1994) A comparison of the diagnostic advantages of panoramic radiography and computed tomography scanning for placement of root form dental implants. Clinical Oral Implants Research, Vol.5, No.4, (December 1994), pp.229-238, ISSN 0905-7161.

Rosenfeld, A. L., Mandelaris, G. A. \& Tardieu, P. B. (2006a) Prosthetically directed implant placement using computer software to ensure precise placement and predictable prosthetic outcomes. Part 1: diagnostics, imaging, and collaborative accountability. International Journal of Periodontics and Restorative Dentistry, Vol.26, No.3, (June 2006), pp.215-221, ISSN 0198-7569.

Shapurian, T., Damoulis, P. D., Reiser, G. M., Griffin, T. J. \& Rand, W. M. (2006) Quantitative evaluation of bone density using the Hounsfield index. International Journal of Oral and Maxillofacial Implants, Vol.21, No.2, (March-April 2006), pp.290-297, ISSN 08822786. 
Turkyilmaz, I., Tumer, C., Ozbek, E. N. \& Tozum, T. F. (2007) Relations between the bone density values from computerized tomography, and implant stability parameters: a clinical study of 230 regular platform implants. Journal of Clinical Periodontology, Vol.34, No.8, (August 2007), pp.716-722, ISSN 0303-6979. 


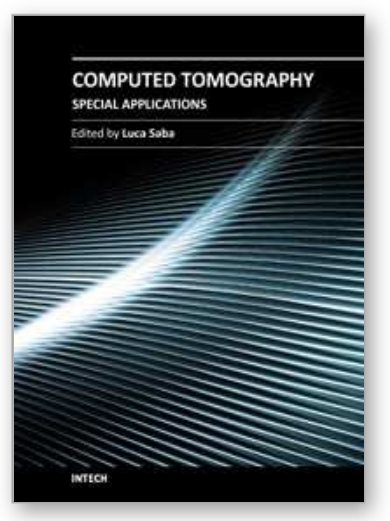

\author{
Computed Tomography - Special Applications \\ Edited by Dr. Luca Saba
}

ISBN 978-953-307-723-9

Hard cover, 318 pages

Publisher InTech

Published online 21, November, 2011

Published in print edition November, 2011

CT has evolved into an indispensable imaging method in clinical routine. The first generation of CT scanners developed in the 1970s and numerous innovations have improved the utility and application field of the CT, such as the introduction of helical systems that allowed the development of the "volumetric CT" concept. Recently interesting technical, anthropomorphic, forensic and archeological as well as paleontological applications of computed tomography have been developed. These applications further strengthen the method as a generic diagnostic tool for non destructive material testing and three dimensional visualization beyond its medical use.

\title{
How to reference
}

In order to correctly reference this scholarly work, feel free to copy and paste the following:

Volkan Arısan (2011). Conventional - and Cone Beam - CT - Derived Stereolithographic Surgical Guides in the Planning and Placement of Dental Implants, Computed Tomography - Special Applications, Dr. Luca Saba (Ed.), ISBN: 978-953-307-723-9, InTech, Available from: http://www.intechopen.com/books/computedtomography-special-applications/conventional-and-cone-beam-ct-derived-stereolithographic-surgical-guidesin-the-planning-and-placeme

\section{INTECH}

open science | open minds

\section{InTech Europe}

University Campus STeP Ri Slavka Krautzeka 83/A 51000 Rijeka, Croatia Phone: +385 (51) 770447 Fax: +385 (51) 686166 www.intechopen.com

\section{InTech China}

Unit 405, Office Block, Hotel Equatorial Shanghai

No.65, Yan An Road (West), Shanghai, 200040, China

中国上海市延安西路65号上海国际贵都大饭店办公楼405单元

Phone: +86-21-62489820

Fax: +86-21-62489821 
(C) 2011 The Author(s). Licensee IntechOpen. This is an open access article distributed under the terms of the Creative Commons Attribution 3.0 License, which permits unrestricted use, distribution, and reproduction in any medium, provided the original work is properly cited. 